\title{
Initiation of hydrogen induced cracks at secondary phase particles
}

\author{
A. Laureys, M. Pinson, L. Claeys, T. De Seranno, T. Depover, K. Verbeken \\ Ghent University, Department of Materials, Textiles and Chemical Engineering, Technologiepark 46, 9052 Zwijnaarde, Belgium \\ aurelie.laureys@ugent.be,margot.pinson@ugent.be,lisa.claeys@ugent.be,tim.deseranno@ugent.be \\ tom.depover@ugent.be (bttps:/ /orcid.org/0000-0002-8856-1122) \\ kim.verbeken@ugent.be (bttps:/ /orcid.org/0000-0002-5190-016X)
}

\begin{abstract}
The goal of this work is to propose a general mechanism for hydrogen induced crack initiation in steels based on a microstructural study of multiple steel grades. Four types of steels with strongly varying microstructures are studied for this purpose, i.e. ultra low carbon (ULC) steel, TRIP (transformation induced plasticity) steel, Fe-C-Ti generic alloy, and pressure vessel steel. A strong dependency of the initiation of hydrogen induced cracks on the microstructural features in the materials is observed. By use of SEM-EBSD characterization, initiation is found to always occur at the hard secondary phase particles in the materials.
\end{abstract}

KEYWORDS. Blisters; Hydrogen induced cracking; particles; Secondary phase; Scanning electron microscopy.

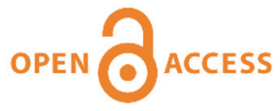

Citation: Laureys, L., Pinson, M., Claeys, L., De Seranno, T., Depover, T., Verbeken, K., Initiation of hydrogen induced cracks at secondary phase particles, Frattura ed Integrità Strutturale, 52 (2020) 113-127.

Received: 18.12 .2019

Accepted: 26.01 .2020 Published: 01.04.2020

Copyright: (C) 2020 This is an open access article under the terms of the CC-BY 4.0, which permits unrestricted use, distribution, and reproduction in any medium, provided the original author and source are credited.

\section{INTRODUCTION}

$\mathrm{E}$ xperimental electrochemical charging of steels with hydrogen mimics, on the one hand, well hydrogen generation and entry in the material from sources such as corrosion or applications such as arc welding [1]. Small amounts of hydrogen in a metal in combination with external or residual stresses can lead to hydrogen embrittlement (HE) or hydrogen assisted cracking (HAC), which results in subcritical failure of the materials [2, 3, 4]. On the other hand, intensive electrochemical charging can induce both surface and internal damage in a material [5]. The hydrogen charging procedure can consequently be applied to simulate situations where hydrogen induced cracking (HIC) takes place. Hydrogen induced internal cracking and blistering can occur in metals subjected to high fugacity hydrogen environments, such as high pressure hydrogen gas environments or under extreme cathodic charging conditions, even without the application of an external load or residual stress, though such stresses can contribute to HIC [5, 6]. HIC occurs, for instance, in oil and gas sour service pipelines where hydrogen ingress into steel from $\mathrm{H}_{2} \mathrm{~S}$ occurs [7]. Also hydrogen flakes as found in reactor pressure vessels [8] are an example of HIC and could be artificially reproduced by intensive electrochemical hydrogen charging [9]. HIC occurs when the hydrogen concentration in the steel matrix exceeds a threshold hydrogen concentration. The threshold hydrogen concentration might be considered as a parameter unique to a given material and strongly depends on the type, shape and amount of inclusions and segregation in the matrix $[10,11,12,13]$. The internal pressure theory $[14,15,16]$ explains the phenomenon of HIC in high fugacity hydrogen environments. The theory states that HIC results from the formation of high pressure hydrogen gas bubbles in internal voids and microcracks. When an alloy is exposed to a hydrogen 
containing environment, atomic hydrogen can be absorbed in the metal and hence diffuses inside the metal. Its movement can be interrupted or hindered by microstructural discontinuities, such as voids, dislocations, second phase particles (such as $\mathrm{MnS}$ [17] inclusions), grain boundaries, and microcracks, which act as trap sites [18]. At such sites, atomic hydrogen can recombine to form molecular gaseous hydrogen, which is incapable of further migration and locally creates a high internal pressure $[14,19]$. A large amount of hydrogen can hence diffuse with time into the traps resulting in a continuously increasing hydrogen pressure. This process is active until an equilibrium in the chemical potential is achieved between the molecular hydrogen in the trap and the hydrogen in the lattice [20]. The result is the formation of overpressurized gas-filled cavities, which cause plastic deformation of the surrounding lattice and promote crack formation. If the internal pressure rises to levels which exceed the tensile strength, crack propagation occurs, even in the absence of externally applied loads. Additionally, lattice hydrogen could facilitate crack propagation at stresses lower than the actual tensile stress of the material by several mechanisms, such as hydrogen-enhanced decohesion (HEDE) [21], hydrogen-enhanced localized plasticity (HELP) [22] or hydrogen-enhanced vacancy formation [23]. The internal pressure is temporarily relieved due to crack propagation, which therefore occurs discontinuously. As proof, some wavy lines perpendicular to the crack propagating directions were observed on the fracture surface of a blister [24, 25]. In a next stage microcracks propagate further and connect, creating a series of stepwise cracks through the material [26]. When the phenomenon takes place close to the sample surface, it is referred to as blistering. The high pressure then pushes material upwards, resulting in a surface blister [5].

Different blister initiation sites and initiation mechanisms have been proposed in literature for alloys charged in a high fugacity hydrogen environment. Numerous studies $[5,6,24,25,27,28]$ revealed that non-metallic inclusions and second phase particles, such as $\mathrm{MnS}$ and $\mathrm{Al}_{2} \mathrm{O}_{3}$, in steels act as major nucleation sites for blisters. Such inclusions typically serve as irreversible trap sites with high binding energies for hydrogen [29, 30], where hydrogen can accumulate. The non-metallic inclusions in steel are usually formed during the steel manufacturing, deoxidation and desulfurization process. Cracking occurs if locally a critical hydrogen concentration necessary for crack initiation is reached [31, 32]. Huang et al. [33] stated that the more hydrogen entrapment occurs in the steel, the more the steel is susceptible to HIC. Elboujdaini and Revie found that a linear relationship exists between the threshold hydrogen concentration in a material and the quantity of inclusions in the steel. Domizzi et al. [34] studied different grades of pipeline steel with various inclusion contents and degrees of microstructural banding through thickness and concluded that the presence of hard bands is more critical than inclusions for HIC. Multiple authors [1, 35, 36] state that the presence of a second phase is not a prerequisite for blister formation and claim that vacancy-hydrogen interaction plays a role in the initiation process as well. Garofalo et al. [37] stated that the hydrogen induced propagation of internal cracks in steel is promoted by hydrogen gas in voids or microcracks which may be formed by plastic deformation or are present as porosities from the casting process. Griesche et al. [1] visualized small pores with diameters of $\sim 1 \mu \mathrm{m}$ all over the hydrogen induced crack surfaces. These pores were located along grain boundaries, which are strong hydrogen traps. In summary, crack nucleation during hydrogen charging has been related to a localized concentration and subsequent recombination of hydrogen at suitable heterogeneities such as grain boundaries, second phase particles, microvoids and tangled dislocations [38].

This investigation gives an overview of previous work $[6,9,39,40]$ in order to bring together results obtained on different materials, compare the initiation mechanism for hydrogen induced cracking and as such give new insights on an important topic. The study compares the blistering behavior of four different types of materials, i.e. ultra low carbon (ULC) steel [6], TRIP (transformation induced plasticity)-assisted steel [40], generic Fe-C-Ti alloy [39], and pressure vessel steels [9]. These materials exhibit strongly varying microstructural features, such as different type of inclusions, precipitates and phases. All these microstructural components interact differently with hydrogen and exhibit a specific critical hydrogen concentration [6]. The aim of this work is to describe a general mechanism for hydrogen induced crack initiation in steels. It is essential to understand the microstructure dependence of HIC to help guide future microstructural design and alloy applications. The materials were cathodically charged as such that damage formed and cross sectional analysis allowed to estimate the initiating internal damage. A thorough microstructural characterization of blisters and internal cracks was performed by optical microscopy, scanning electron microscopy (SEM) and electron backscatter diffraction (EBSD).

\section{EXPERIMENTAL PROCEDURE}

\section{Materials}

$\checkmark$ he hydrogen induced cracking behavior of five different steel alloys was compared during the current investigation, i.e. ultra-low carbon (ULC) steel, TRIP (transformation induced plasticity)-assisted steel, generic Fe-C-Ti alloy and two types of pressure vessel steels. The chemical compositions of these materials are given in Tab. 1 and 2. 


\begin{tabular}{cccccccccc}
\hline $\mathbf{W t} \%$ & $\mathbf{S}$ & $\mathbf{C}$ & $\mathbf{N}$ & $\mathbf{P}$ & $\mathbf{M n}$ & $\mathbf{T i}$ & $\mathbf{A l}$ & $\mathbf{S i}$ & $\mathbf{F e}$ \\
ULC steel & $38 \mathrm{ppm}$ & $214 \mathrm{ppm}$ & $88 \mathrm{ppm}$ & $73 \mathrm{ppm}$ & 0.25 & 0.002 & 0.047 & & Balance \\
TRIP steel & & 0.17 & & $0.04-0.1$ & 1.60 & & $1-2$ & 0.40 & Balance \\
Fe-C-Ti steel & & 0.1 & $50 \mathrm{ppm}$ & & & 0.38 & 0.03 & & Balance \\
\hline
\end{tabular}

Table 1: Chemical composition of ULC steel, TRIP-assisted steel and Fe-C-Ti steel.

\begin{tabular}{ccccccc}
\hline $\mathbf{W t} \%$ & $\mathbf{C}$ & $\mathbf{S i}$ & $\mathbf{M n}$ & $\mathbf{P}$ & $\mathbf{S}$ & $\mathbf{C r}$ \\
& $\leq 0.25$ & $0.10-0.30$ & $1.15-1.55$ & $\leq 0.015$ & $\leq 0.012$ & $\leq 0.25$ \\
$\mathbf{W t} \%$ & $\mathbf{C u}$ & $\mathbf{M o}$ & $\mathbf{N i}$ & $\mathbf{V}$ & $\mathbf{A l}$ & $\mathbf{F e}$ \\
& $\leq 0.20$ & $0.45-0.55$ & $0.50-0.80$ & $\leq 0.03$ & $\leq 0.04$ & Balance \\
\hline
\end{tabular}

Table 2: Chemical composition range specifications for the two pressure vessel alloys ( $\mathrm{wt} \%$ ).

Ultra-low carbon steel was used as a material of study in order to avoid the effect of complex microstructural characteristics on blister/internal crack characterization. A cold deformed ULC steel is studied in the current study, since controllable introduction of blisters is possible in this material [6]. The corresponding microstructure is shown in Fig. 1. This material consists of deformed ferrite grains and a small number of $\mathrm{Al}_{2} \mathrm{O}_{3}$ inclusions. Only a few hydrogen trapping sites are present in this material, i.e. grain boundaries, dislocations, vacancies, microvoids and additionally, some inclusions.

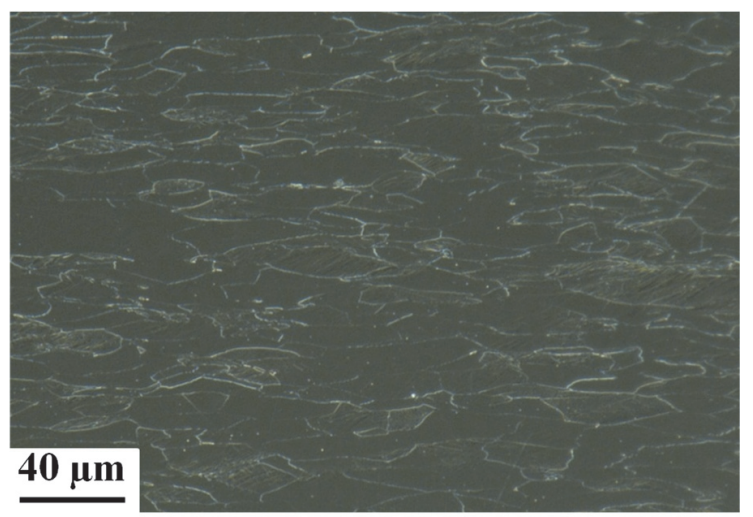

Figure 1: Dark field optical microscopy image of cold deformed ULC steel. Reprinted with permission from Ref. [6].

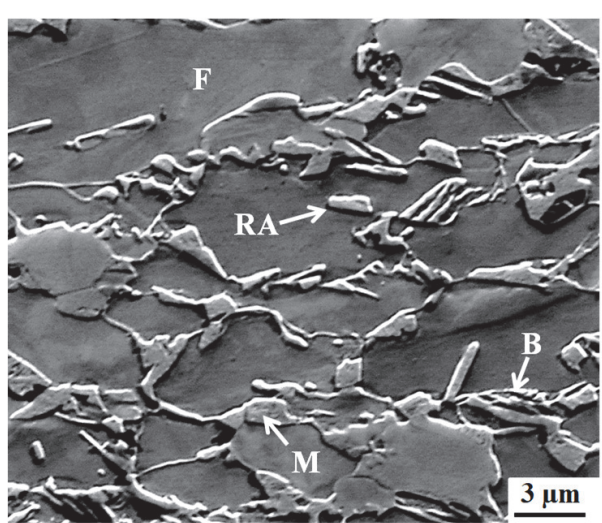

a)



b)

Figure 2: SEM image of a) TRIP assisted steel (RA: retained austenite, M: martensite, F: ferrite, B: bainite) and b) original AlN inclusions/voids in the steel. Reprinted with permission from Ref. [40].

Contrary to ULC steel, TRIP-assisted steel has a complex multiphase microstructure with a ferritic matrix and a dispersion of multiphase grains of bainite, retained austenite and some martensiet [41] (Fig. 2). The ferritic grains appear as big, flat 
grains. The retained austenite grains remain unetched so they exhibit a smooth appearance, while martensite exhibits a rough appearance. Finally, bainite can be detected by its lamellar structure containing bainitic ferrite and retained austenite [42]. Additionally, some large voids and inclusions were found in the material as well, as shown in Fig. 2b. The inclusions were characterized as AlN by energy dispersive X-ray analysis.

A laboratory cast, hot and cold rolled ferritic Fe-C-Ti material was also investigated. The generic lab-cast alloy possesses a well-specified chemical composition and was submitted to a well-defined thermal treatment. Carbides/carbonitrides in a coarse grained recrystallized ferritic matrix were as such obtained (Fig. 3)., which allows to study the effect of precipitates without the additional trapping effects of phase boundaries, such as martensitic lath boundaries, or the presence of an increased dislocation density. Large incoherent carbonitrides $(2-5 \mu \mathrm{m})$, medium-sized carbonitrides $(\operatorname{Ti}(\mathrm{C}, \mathrm{N}))(100-700 \mathrm{~nm})$ and small carbides (2-24 nm) were found in the material (Fig. 3 and 4) [39].

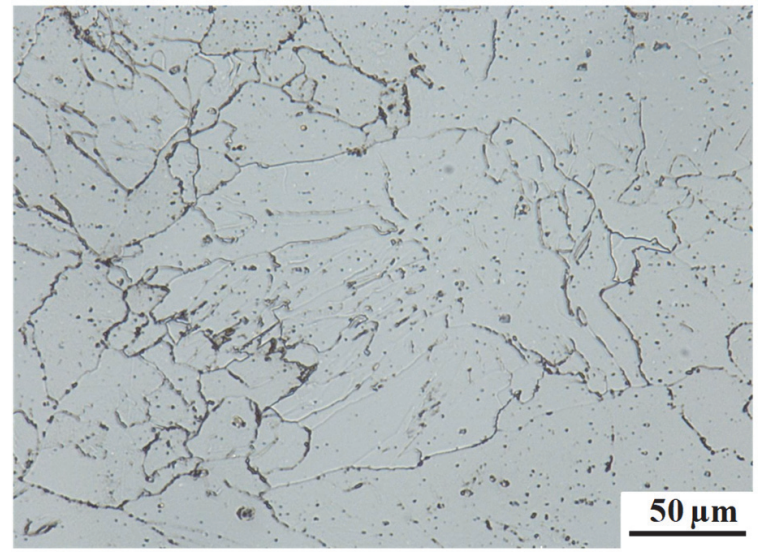

Figure 3: Bright field optical microscopy image of the microstructure of a generic Fe-C-Ti alloy. Reprinted with permission from Ref. [39].

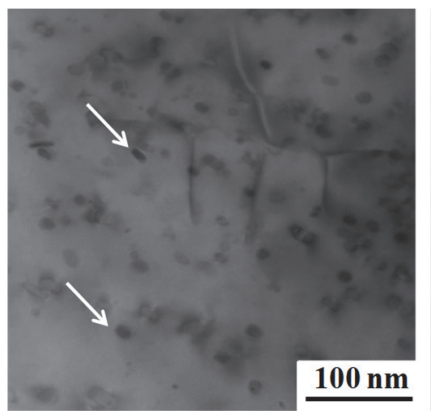

a)

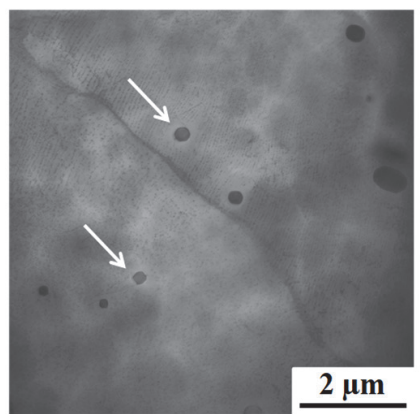

b)

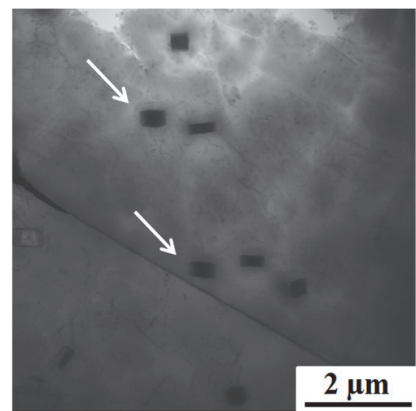

c)

Figure 4: Bright field STEM images of a) small TiC, b) larger spherical Ti(C,N), and c) square Ti(C,N) (indicated with arrows). Reprinted with permission from Ref. [39].

Two industrial pressure vessel steels were studied as well (material A and B). The essential difference in composition for these two alloys is the sulphur content, which was $0.003 \mathrm{wt} \%$ for material A and $0.008 \mathrm{wt} \%$ for material $\mathrm{B}$. These high hardenability steels were demonstrated to be severely prone to hydrogen induced cracking [43]. These materials exhibit large segregation zones, both macro- and micro-segregation, since they originate from large forgings. Such segregation zones are formed during the casting process and are further deformed by the subsequent manufacturing processes, such as forging [8]. Due to the long time required for solidification, large ingots tend to have a larger degree of segregation compared to smaller ingots. Internal stresses are created as a result of cooling, applied strain and phase transformation. Due to the enrichment in alloying elements in these regions, a significant amount of $\mathrm{MnS}$ is present. The shape and the location of the macro- and micro-segregation zones differed for both materials due to a different manufacturing history, i.e. hollow ingot casting for material $\mathrm{A}$ and solid ingot casting followed by a piercing operation for material $\mathrm{B}$. The microstructure of material $\mathrm{A}$ and $\mathrm{B}$ was nevertheless very similar and the banded structure is visualized in Fig. 5, where the darker regions are the micro-segregation regions, i.e. ghost lines. The segregation areas solidified last after casting and are, therefore, enriched with 
solutes. Non-segregated regions exhibited a tempered bainitic microstructure with little ferrite, while segregation zones consist of tempered martensite and bainite originating from the last solidified regions. In the segregation zones inclusions were found and identified as manganese sulfides (MnS) (Fig. 6). Comparing both materials, it is found that material A exhibited a lower number density of inclusions than material B. This can be correlated to the lower sulfur content of material A compared to material B, which does not influence the particle size, but does influence the number of particles [44]. Additionally, the inclusions were also more strongly elongated in material B compared to material A. The corresponding elongation ratios were 3.68 and 2.46, respectively. The average prior austenite grain sizes were $20.0 \mu \mathrm{m}$ and $15.4 \mu \mathrm{m}$ for material A and B, respectively. Due to the strongly heterogeneous distribution of the micro-segregation areas in the materials, the precise quantification of the phase fractions could not be characterized in a reliable manner. After a qualitative study, it was clear that material A exhibited more tempered martensite in the segregated zones than material B [9].

\section{Electrochemical bydrogen charging}

Oval shaped samples with a major axis of $20 \mathrm{~mm}$ and a minor axis of $15 \mathrm{~mm}$ were machined from the plate materials (for TRIP-assisted steels (0.65 mm thickness), ULC steel (1.2 $\mathrm{mm}$ thickness) and Fe-C-Ti steel (1 mm thickness). The major axis of the samples coincides with the rolling direction of the plates. For the pressure vessel steels, circular (20 mm diameter) samples were machined from the macro-segregated areas in a large forging, which contain local micro-segregated zones, i.e. ghost lines. Subsequently, the samples were ground to a final thickness of $1.1 \mathrm{~mm}$. The samples' surfaces and edges were ground prior to hydrogen charging to remove possible oxides. The removal of surface oxides is required, since they exhibit an inhibiting effect on hydrogen transport to the metal surface and as such possibly affect the nucleation and propagation of hydrogen induced cracks [45].

The samples were cathodically charged with hydrogen in a polycarbonate cell containing $0.5 \mathrm{M} \mathrm{H}_{2} \mathrm{SO}_{4}$ and $1 \mathrm{~g} / 1$ thiourea electrolyte. Thiourea was added to the electrolyte in order to promote hydrogen atom absorption into the metal rather than hydrogen recombination to its molecular form at the surface. The sample was connected as a cathode and positioned symmetrically in between two platinum anodes. Samples were charged at room temperature using a charging current density of $10 \mathrm{~mA} / \mathrm{cm}^{2}$. The charging times varied for different materials (ranging from 1 to 4 days), since the materials each had a different sensitivity to hydrogen induced damage and optimal charging times were selected to induce hydrogen cracks into the samples. Each specific charging condition was applied multiple times to confirm the repeatability of the crack characteristics.

\section{Hydrogen induced crack investigation}

Surface imaging by optical microscopy allowed the detection of blisters on the sample surfaces. Cross sections along the transverse direction plane were analyzed in order to obtain information on the internal cracks in the hydrogen charged samples. These sections were polished using standard metallographic techniques and subsequently etched with Nital $2 \%$ for 10s. A first preliminary investigation of the internal microstructural damage was performed by optical microscopy, followed by a SEM study. Subsequently, the most interesting features were investigated with EBSD using a scan step size ranging from 0.05 and $0.1 \mu \mathrm{m}$ on a hexagonal grid. For the EBSD investigation, an additional polishing step with colloidal silica was required. In the current study two OIM data processing maps, namely phase map and kernel average image quality (KAIQ) were implemented and analyzed. Kernel average image quality was used to make a clear distinction between martensite and cracks in TRIP-assisted steels, which is complicated because they both exhibit a confidence index (CI) lower than 0.1.

\section{RESULTS AND DISCUSSION}

he five materials were charged at $10 \mathrm{~mA} / \mathrm{cm}^{2}$ for certain charging times (Fig. 7), so to induce a considerable amount of hydrogen induced damage in the materials. As such, cross sections would allow to study in depth the mechanisms of crack initiation. Since each material had a different sensitivity to hydrogen induced damage, charging times varied. The variable sensitivity is caused by the different microstructures of the materials, which exhibit varying hydrogen trapping characteristics. Huang et al. [46] and Dong et al. [47] actually revealed that the HIC susceptibility depends on the hydrogen entrapment in steel. The surface distribution of the blisters will be discussed in more detail for each material separately, together with cross section analysis in the next section, so that the distribution can be related to the microstructure of the material. 


\section{Non-segregated region}

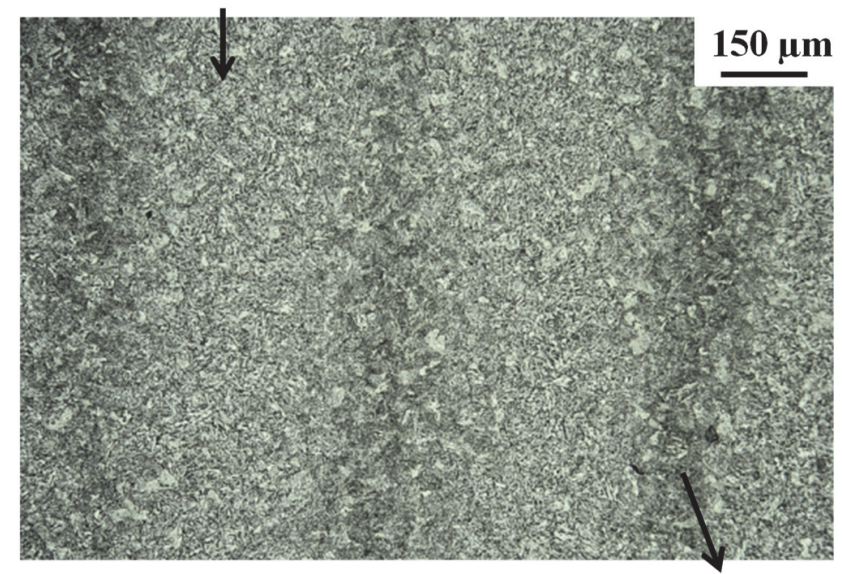

a)

Segregated region

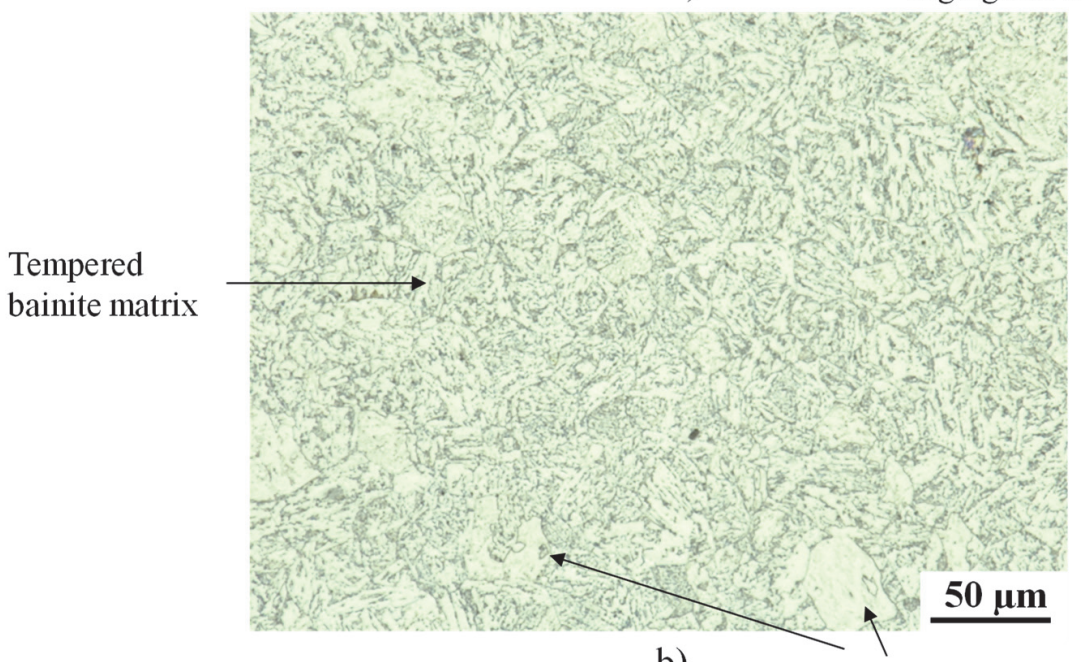

b) Ferrite islands

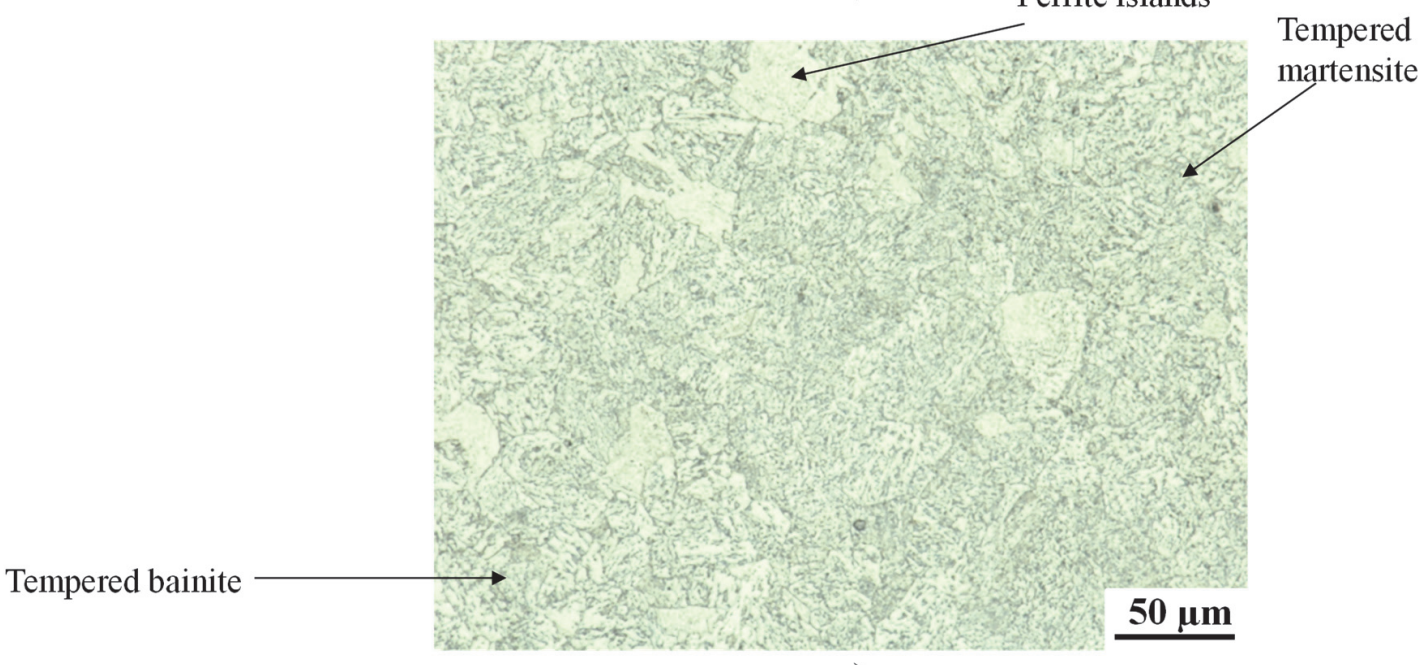

c)

Figure 5: a) banded structure, b) non-segregated region, and c) micro-segregated region typically observed in material A. Material B showed similar microstructure. Reprinted with permission from Ref. [9]. 

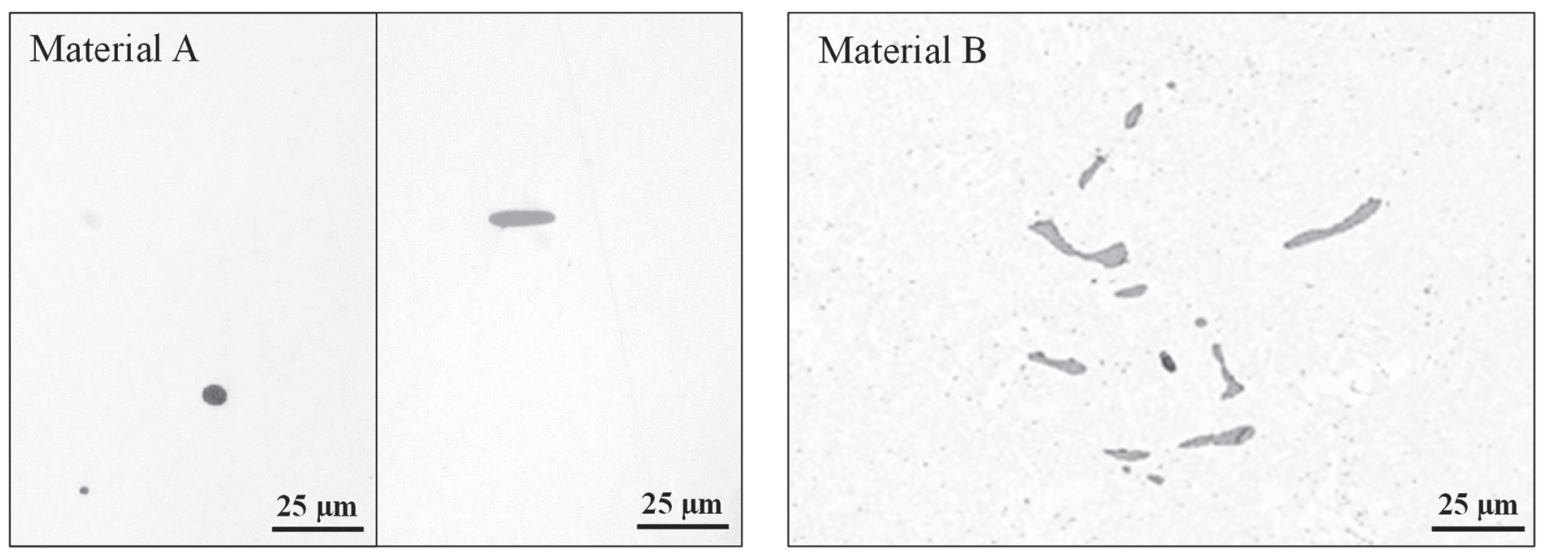

Figure 6: MnS inclusions in a segregation region in material A and B. The samples were polished to better distinguish the MnS inclusions. Reprinted with permission from Ref. [9].

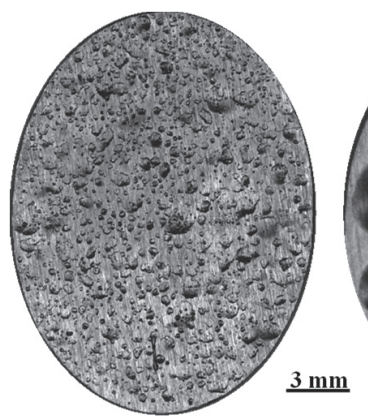

a)

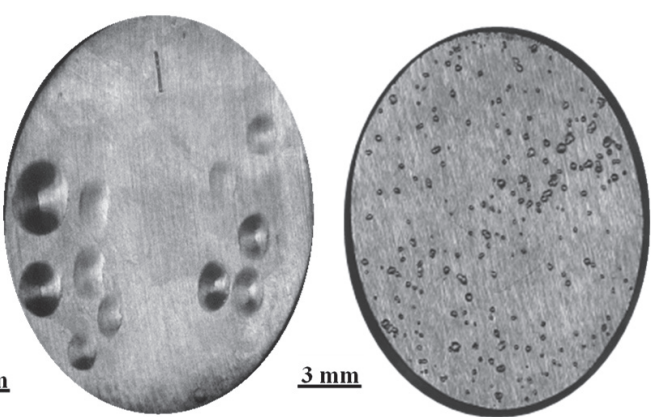

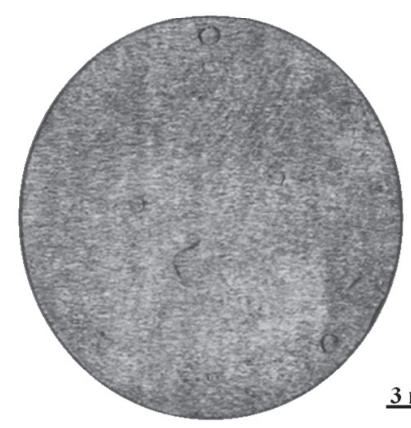

d) c)

b)

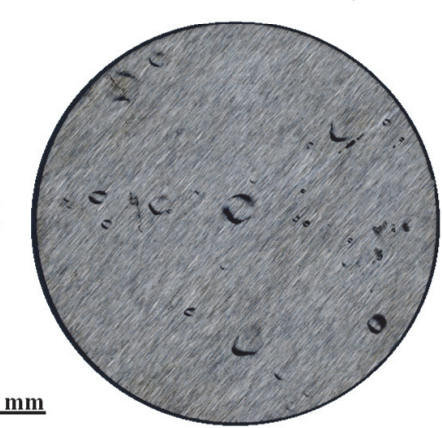

e)

Figure 7: a) Deformed ULC steel hydrogen charged at $10 \mathrm{~mA} / \mathrm{cm}^{2}$ for 2 days; b) TRIP-assisted steel hydrogen charged at $10 \mathrm{~mA} / \mathrm{cm}^{2}$ for 3 days, c) Fe-C-Ti alloy hydrogen charged at $10 \mathrm{~mA} / \mathrm{cm}^{2}$ for 1 day, d) and f) pressure vessel steel material A and B, respectively, charged with hydrogen at $10 \mathrm{~mA} / \mathrm{cm}^{2}$ for 4 days. Reprinted with permission from Ref. [6, 39].

Hydrogen induced crack initiation was studied for the different materials by analyzing cross sections of hydrogen charged materials under the conditions of Fig. 7. A strong dependence of hydrogen induced cracking to the microstructure was found. The initiation will be discussed for each separate material, followed by a comparative study. In order to further characterize the role of microstructural features on blister formation, cross sections were studied by a combination of SEM and EBSD.

\section{ULC steel}

Crack initiation in cold deformed ULC steel was often observed at inclusions (Fig. 8). More specifically, interface debonding led to the initiation of cracks. The particles were identified by energy dispersive X-ray spectroscopy (EDX) as alumina particles, which originate from the typically performed desoxidation step in the steel production process. Cracks were often observed with large alumina particles along them (Fig. 8b). 


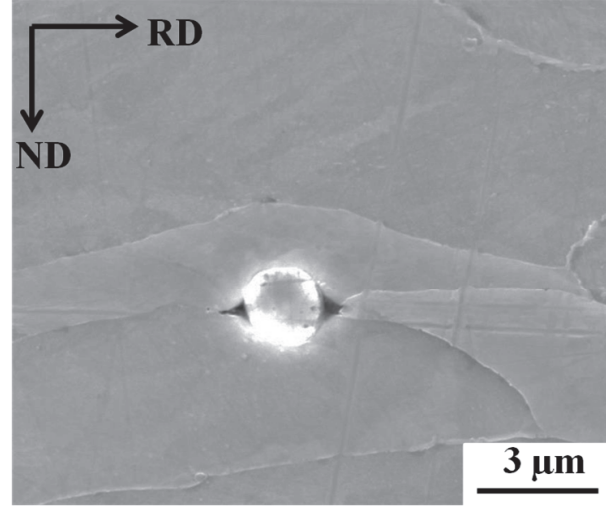

a)

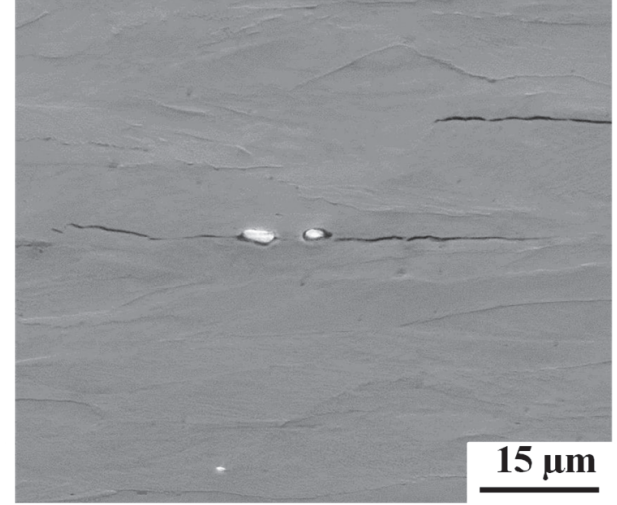

b)

Figure 8: a) Crack initiation at alumina particle and b) particles along cracks in deformed ULC steel. Reprinted with permission from Ref. [6].

Tiegel et al. [25] proposed a mechanism which could explain the observed phenomenon. They stated that hydrogen accumulation occurs at the incoherent particle interfaces, causing interface failure. Subsequently, vacancy stabilization at the interfaces occurs due to the increased hydrogen concentration, as such providing space around the inclusions for hydrogen atoms to form molecular hydrogen. The resulting internal pressure then drives the material to form a crack. The proposed mechanism is illustrated in Fig. 9, which is similar to what was observed in the samples (Fig. 8a). Moreover, Jin et al. [11] and Kim et al. [48] stated that relatively big voids exist between an inclusion and the steel substrate, which acts as sinks for the hydrogen atoms, resulting in high local stress concentration due to formation of hydrogen molecules. Consequently, interfacial decohesion is stimulated with increasing hydrogen segregation.
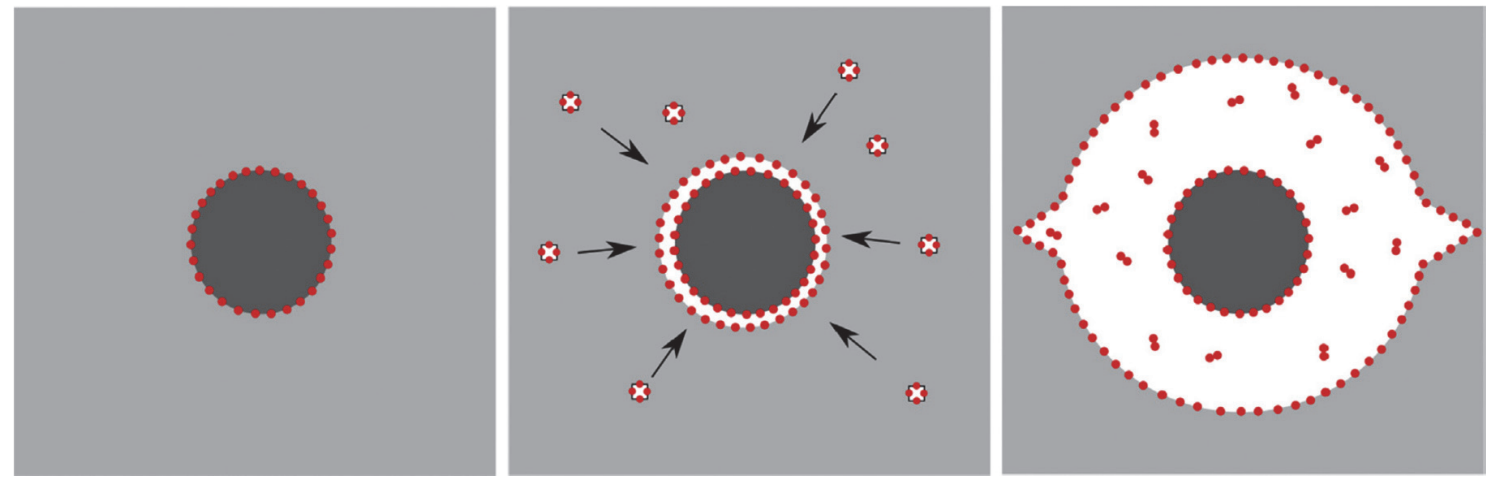

Figure 9: Sketch of proposed mechanism for crack initiation by Tiegel et al. [25]. Reprinted with permission from Ref. [6].

Fig. 7 shows that deformed ULC steel is very sensitive to crack initiation, since numerous small blisters are found on the surface of hydrogen charged samples, even though only a limited amount of inclusions are present in the material. In cold deformed material, inclusions will exhibit an increased concentration of dislocation tangles at the interface with the matrix due to impingement. A resulting local increase in the hydrogen concentration as such exists at the interface, leading to enhanced crack initiation. Additionally, in cold deformed material a larger number of vacancies is present, which will equally accelerate the abovementioned mechanism. All the blisters observed on the surface cannot be initiated at inclusions, since the number of inclusions in the material is not that high. Initiating cracks were also found on slip planes or grain boundaries, not in the immediate vicinity of inclusions (Fig. 10). In a strongly deformed material such as the ULC steel studied here, dislocation tangles could also act as hydrogen induced crack initiation locations. More details concerning the blistering behavior of deformed ULD steel can be found in [6]. 


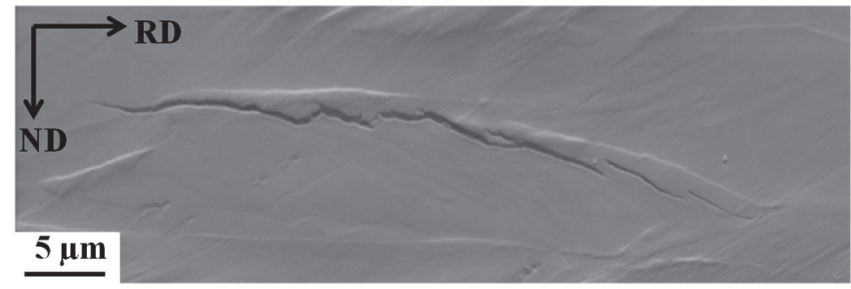

a)

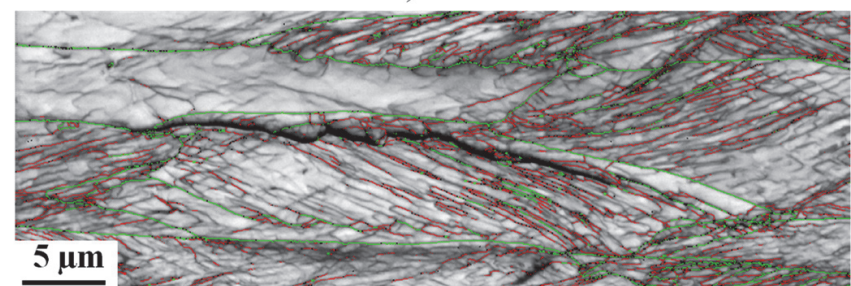

b)

Figure 10: Early stage of cracking in hydrogen charged cold deformed ULC steel ( $5 \mathrm{~mA} / \mathrm{cm}^{2}-2$ days). a) SEM image, b) IQ map with HAGBs $\left(>15^{\circ}\right)$ in green and LAGBs (low angle grain boundaries) $\left(5-15^{\circ}\right)$ in red. Reprinted with permission from Ref. [6].

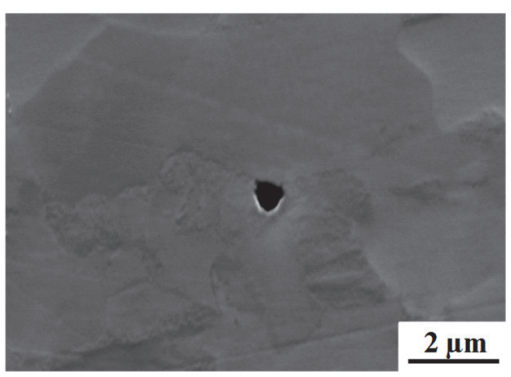

a)

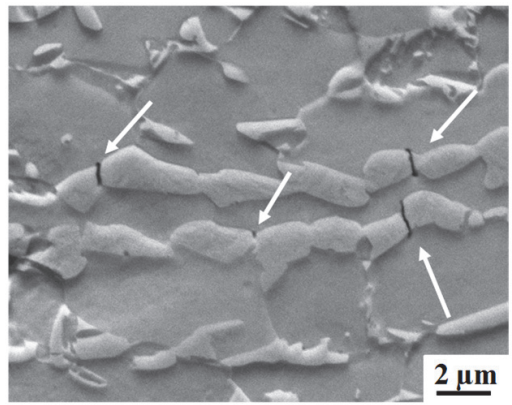

c)

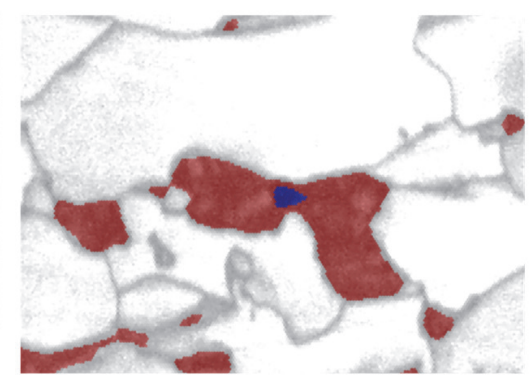

b)

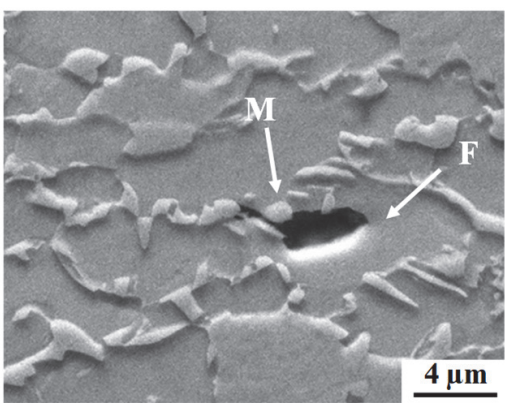

d)

Figure 11: TRIP-assisted steel hydrogen charged for 1 day at $10 \mathrm{~mA} / \mathrm{cm}^{2}$ : a) SEM image and b) Kernel average image quality (KAIQ) overlapped with an IQ map of the investigated zone (Blue: cavity $(610<\mathrm{KAIQ}<780)$, red: martensite $(780<\mathrm{KAIQ}<1115))$. c) Hydrogen void initiation at martensite (indicated by white arrows). d) Initiating crack arrested in ferritic grain (M: martensite island, F: ferrite grain). Reprinted with permission from Ref. [40].

\section{TRIP-assisted steel}

Fig. 11 shows that the martensite-martensite interface is a preferential initiation site for hydrogen induced void formation in the studied TRIP-assisted steel charged under the current conditions. A kernel average image quality map allowed to identify the martensitic phase (Fig. 11b). Small voids formed at notches between two martensitic islands [40]. This fracture behavior was also observed when studying hydrogen assisted cracking in TRIP-assisted steel where an external stress is applied on samples charged up to saturation. The authors claimed that initiation occurred by the HEIDE mechanism (Hydrogen Enhanced Interface Decohesion) [2], which is a HEDE related mechanism as decohesion occurs across the interface. Koyama et al. [49] made similar observations in hydrogen charged dual phase steel under stress. Chan [50] illustrated that a fresh martensitic structure is the one most susceptible to hydrogen embrittlement. The lath martensite has 
a large density of dislocations $\left(10^{11}\right.$ to $\left.10^{12} \mathrm{~cm}^{-2}\right)$ and residual micro-stresses and thus displays a large hydrogen trapping capacity [50]. Additionally, these regions are surrounded by transformation induced stresses and lattice defects [50], which makes these regions preferential sites for hydrogen accumulation and damage initiation. From the experimental observation, the martensite-martensite interface is the most favorable crack initiation location. The interface is highly strained and most likely a preferential place for hydrogen accumulation. Even though large AlN inclusions were present in the material, these particles were not crack initiation sites.

Small initiating cracks were found over the whole cross section of the samples, but initiating cracks were often arrested when propagating from martensite into ferritic zones (Fig. 11c and d). Plastic deformation of the softer ferritic phase resulted in crack blunting and arrest (Fig. 11d). Such small cracks did not result in the appearance of a blister on the sample surface. Crack propagation was only favorable along the segregation line of the samples, which consisted of a continuous crack sensitive martensitic network (Fig. 12). So even though numerous crack initiation sites are found, only a limited amount of larger hydrogen induced cracks form. This results in a limited number of large blisters at the sample surface, which can be seen in Fig. $7 b$.

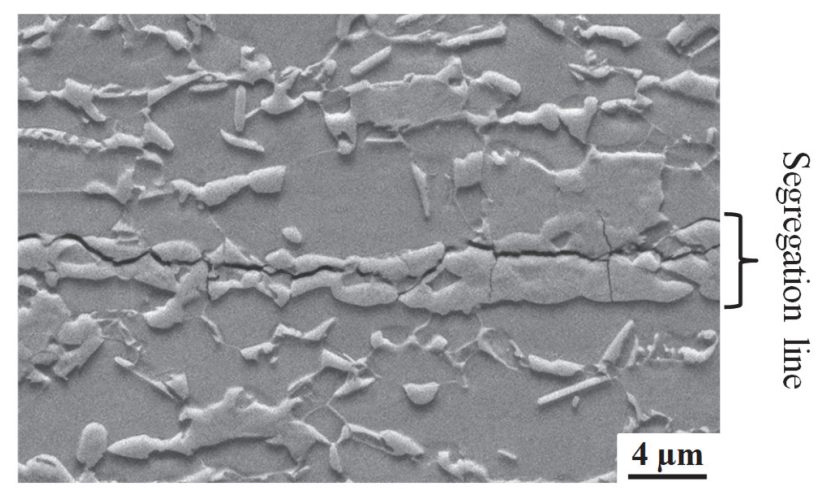

Figure 12: SEM image of hydrogen induced cracking along the segregation line of TRIP-assisted steel. Reprinted with permission from Ref. [40].

\section{Fe-C-Ti alloy}

Cross section investigation of Fe-C-Ti showed that initiation was related to the intermediate and large titanium precipitates, i.e. Ti(C,N) (Fig. 13). Most often clusters of precipitates were involved [39]. Terasaki et al. [24] also observed a greater HIC sensitivity at clusters of inclusions. Ren et al. [24] stated that Ti containing precipitates can act as nucleation sites for blisters. The precipitates act as hydrogen traps [36, 51], which implies that at these locations an increased amount of hydrogen is present and during continuous hydrogen charging under severe conditions, recombination of hydrogen atoms will occur within the precipitates, leading to fracture of the particles.

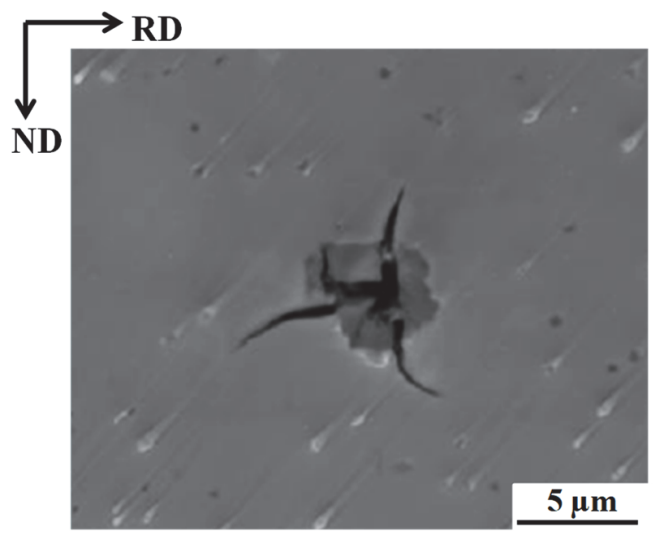

Figure 13: SEM image of blister initiation at large precipitates $(\mathrm{Ti}(\mathrm{C}, \mathrm{N}))$ in Fe-C-Ti alloy. Reprinted with permission from Ref. [39].

A clear interaction of cracks with large Ti-based precipitates was demonstrated as well with EBSD (Fig. 14) [39]. Most likely the hydrogen induced cracking initiated at the large carbides/carbonitrides, due to hydrogen build-up at the interface or in the precipitates. 


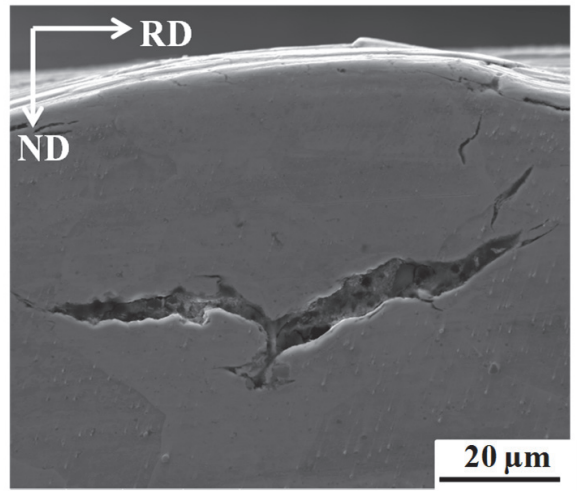

a)

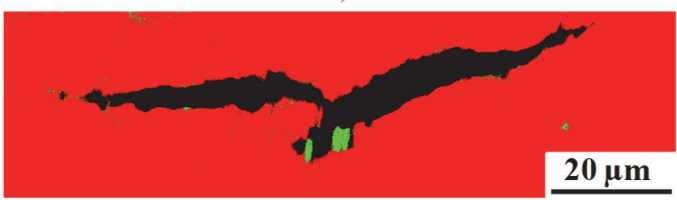

b)

Figure 14: Crack interaction with Ti-based precipitates in Fe-C-Ti charged for one day at $10 \mathrm{~mA} / \mathrm{cm}^{2}$ : a) SEM image, b) EBSD phase map. Reprinted with permission from Ref. [39].

The microstructural investigation by optical microscopy of this material (Fig. 3) showed that the large inclusions are present in abundance. The presence of such a large amount of initiation locations, makes this material very sensitive to hydrogen induced crack initiation. Moreover, the ductile ferritic phase retards further crack propagation due to crack blunting, therefore, crack initiation of brittle inclusions is rather promoted over crack propagation. Initiation of new blisters is as such preferred over growth of already existing blisters in the present material, which is clearly demonstrated by the large number of small blisters found on the sample surface (Fig. 7c).

\section{Pressure vessel steel}

For both pressure vessel steels $\mathrm{MnS}$ was the favorable initiation location. Multiple MnS inclusions were found to exhibit decohesion at the interface between the inclusions in the segregation zones and the matrix (Fig. 15). The MnS along cracks were identified by EDX (Fig. 16) [9]. On the one hand, the observed decohesion could have occurred prior to hydrogen charging, since MnS inclusions have a weak bonding with the matrix, due to their considerable contraction upon cooling. The formation of cavities would, therefore, be expected to be facilitated at these locations under conditions of minor strain [52]. When charged with hydrogen, hydrogen could accumulate and recombine at these interfaces, which results in crack initiation. On the other hand, the defect concentration surrounding the elongated inclusions is higher than the matrix concentration due to a different thermal expansion coefficient and deformation incompatibility during forging, providing an increased amount of trapping locations for hydrogen [29]. The MnS inclusions are significantly more deformable than other inclusion types, so they elongate to larger sizes during forging. If a crack nucleates around these elongated inclusions, the resulting stress concentration is more severe than for smaller, globular inclusions [29]. Hydrogen trapping and resulting recombination to hydrogen gas at the matrix/inclusion interface could occur, which insinuates that the interfaces of the inclusions with the matrix are the actual initiation sites for hydrogen flakes (Fig. 15a). The mechanism observed here strongly resembles the features observed in deformed ULC steel and the theory of Tiegel et al. [25] could also be applied here. When charging the two materials under the same charging conditions, material B exhibited a different blistering behavior than material A. The size distribution of the formed blisters was different for both materials. Material B showed a larger number of blisters, but smaller in size than the blisters found on material A (Fig. 7). This difference could be attributed to a larger amount of crack initiation locations (i.e. MnS inclusions) present in material B. More cracks will initiate simultaneously without having the time to extensively grow, this in contrast to when only a limited amount of initiation locations are present and hydrogen is more concentrated leading to the formation of larger blisters. Additionally, more tempered martensite was present in the segregation zones of material A which stimulated crack propagation, since this phase is particularly sensitive to hydrogen induced cracking [2, 50, 53]. Vorob'ev et al. [44] claimed that a decrease in the number of sulfide inclusions would result in an increase of the hydrogen volume per inclusion. As such, a larger $\mathrm{H}_{2}$ gas pressure 
build-up occurs at the inclusion/matrix interface, which would indeed result in larger cracks. The more elongated sulfides in material $\mathrm{B}$ are expected to be more sensitive to cracking, since their long edges provide longer peripheries for $\mathrm{H}$ trapping [34] and larger stress concentrations form around the inclusions [44].

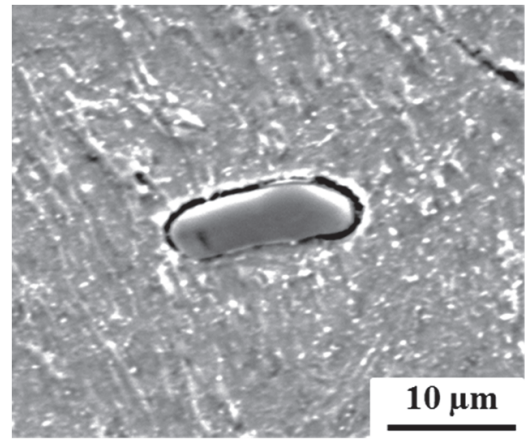

a)

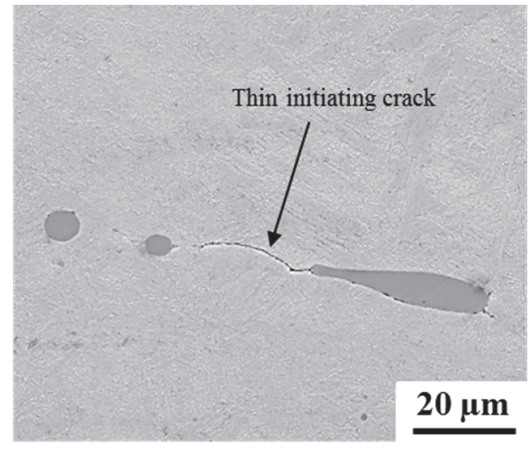

b)

Figure 15: SEM images of initiating hydrogen induced cracks in pressure vessel steel: a) Interface decohesion at a MnS inclusion. b) crack initiation at $\mathrm{MnS}$ in material A. Reprinted with permission from Ref. [9].

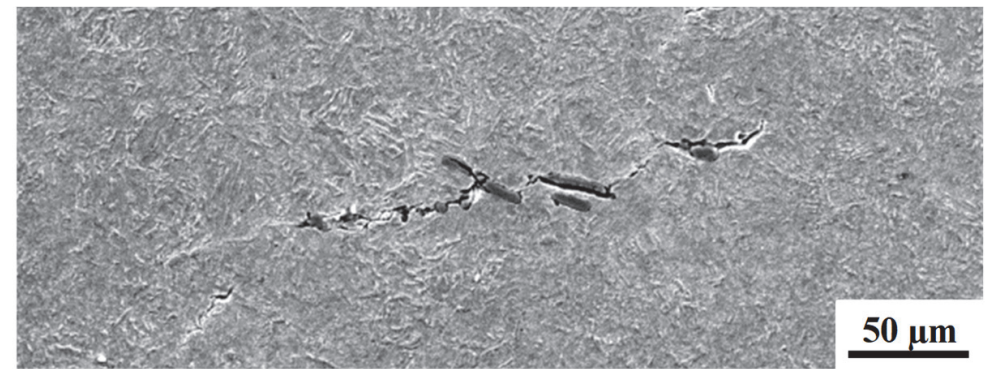

a)

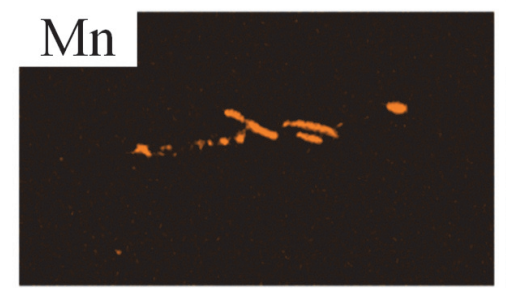

b)

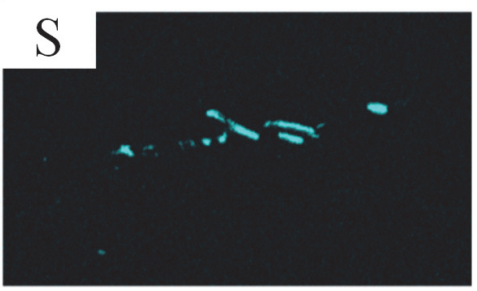

c)

$50 \mu \mathrm{m}$

Figure 16: Initiating hydrogen induced crack in pressure vessel steel: a) Cracking along MnS inclusions in material A. b) and c) EDX analysis confirming the presence of $\mathrm{MnS}$ in the crack. Reprinted with permission from Ref. [9].

\section{CONCLUSIONS}

$\mathrm{H}$

ydrogen induced crack initiation was found to be strongly microstructure dependent. In the four types of materials, initiation occurred by either debonding or fracture of inclusions or hard secondary phases in the material. Following main conclusions could be drawn:

Initiation at non-metallic inclusions took place in deformed ULC steel (i.e. $\mathrm{Al}_{2} \mathrm{O}_{3}$ particles) and pressure vessel steels (i.e. MnS inclusions). Interface debonding led to HIC initiation. The inclusions exhibit different thermal expansion coefficients and deformation incompatibility compared to the steel matrix, which leads to local stress accumulation, deformation induced defects and interface decohesion during thermomechanical processing of the materials. As such, the interfaces act as strong/irreversible trapping sites for hydrogen in comparison to the surrounding matrix. HIC along those interfaces is promoted by the increased hydrogen concentration. 
- Initiation took place at hard secondary phases in TRIP-assisted steel, i.e. martensitic islands, and in generic Fe-CTi alloys, i.e. Ti-based precipitates. Fracture of the hard secondary phase led to HIC initiation. These secondary phases act as strong/irreversible trapping sites for hydrogen in comparison to the matrix. Hydrogen accumulation occurs more readily at these locations and due to the intrinsic brittleness of the hard secondary phases, HIC is favored.

- Strong irreversible traps attract the most hydrogen, which can, in case of a continuous hydrogen supply, recombine to molecular hydrogen at these positions. The molecular hydrogen in turn creates an internal pressure in the material, which promotes the fracture of brittle secondary phase particles or debonding of inclusion interfaces with the matrix. Moreover, features such as martensite, inclusions, and slip planes are intrinsically more sensitive to fracture than the matrix.

In order to avoid or decrease the HIC susceptibility of materials, strong irreversible traps should be avoided in the materials. A homogeneous microstructure with reduced inclusions or hard phases would lead to an increased HIC resistance.

\section{ACKNOWLEDGEMENTS}

1. Depover holds a senior postdoctoral fellowship of the Research Foundation - Flanders (FWO) via grant $12 Z O 420 \mathrm{~N}$. The authors also acknowledge support from the FWO SB PhD fellow of L. Claeys via grant 1 S16618N. The authors also wish to thank the Special Research Fund (BOF), UGent (grant BOF15/BAS/062 and BOF01P03516).

\section{REFERENCES}

[1] Griesche, A., Dabah, E., Kannengiesser, T., Kardjilov, N., Hilger, A., Manke, I. (2014). Three-dimensional imaging of hydrogen blister in iron with neutron tomography, Acta Mater., 78, pp. 14-22.

DOI: 10.1016/J.ACTAMAT.2014.06.034.

[2] Laureys, A., Depover, T., Petrov, R., Verbeken, K. (2016). Microstructural characterization of hydrogen induced cracking in TRIP-assisted steel by EBSD, Mater. Charact., 112, pp. 169-179. DOI: 10.1016/j.matchar.2015.12.017.

[3] Depover, T., Pérez Escobar, D., Wallaert, E., Zermout, Z., Verbeken, K. (2014). Effect of in-situ hydrogen charging on the mechanical properties of advanced high strength steels, Int. J. Hydrog. Energy, 39, pp. 4647-4656. DOI: 10.1016/j.ijhydene.2013.12.190 .

[4] Depover, T., Wallaert, E., Verbeken, K. (2016). Fractographic analysis of the role of hydrogen diffusion on the hydrogen embrittlement susceptibility of DP steel, Mater. Sci. Eng. A, 649, pp. 201-208. DOI: 10.1016/j.msea.2015.09.124 .

[5] Pérez Escobar, D., Miñambres, C., Duprez, L., Verbeken, K., Verhaege, M. (2011). Internal and surface damage of multiphase steels and pure iron after electrochemical hydrogen charging, Corros. Sci., 53, pp. 3166-3176. DOI: 10.1016/J.CORSCI.2011.05.060.

[6] Laureys, A., Van den Eeckhout, E., Petrov, R., Verbeken, K. (2017). Effect of deformation and charging conditions on crack and blister formation during electrochemical hydrogen charging, Acta Mater., 127, pp. 192-202.

DOI: 10.1016/J.ACTAMAT.2017.01.013.

[7] Findley, K. O., O’Brien, M. K., Nako, H. (2015). Critical Assessment 17: Mechanisms of hydrogen induced cracking in pipeline steels, Mater. Sci. Tech., 31, pp. 1673-1680. DOI: 10.1080/02670836.2015.1121017

[8] De Bruycker, E., De Vroey, S., Huysmans, S., Stubbe, J. (2014). Phenomenology of hydrogen flaking in nuclear reactor pressure vessels, Mater. Test., 56, pp. 439-444. DOI: 10.3139/120.110580.

[9] Laureys, A., Van Stappen, J., Cnudde, V., Verbeken, K. (2019). Electrochemical hydrogen charging to simulate hydrogen flaking in pressure vessel steels, Eng. Fract. Mech., 217, pp. 106546. DOI: 10.1016/J.ENGFRACMECH.2019.106546.

[10] Boukharouba, T. et al. (eds.), (2009). Effect of Non-Metallic Inclusions on Hydrogen Induced Cracking, In: Damage and Fracture Mechanics: Failure Analysis of Engineering Materials and Structures, Ontario, Springer Science + Business media B.V., pp. 11-18. DOI: 10.1007/978-90-481-2669-9_2.

[11]Jin, T.Y., Liu, Z.Y., Cheng, Y.F. (2010). Effect of non-metallic inclusions on hydrogen-induced cracking of API5L X100 steel, Int. J. Hydrog. Energy, 35, pp. 8014-8021. DOI: 10.1016/j.ijhydene.2010.05.089.

[12] Fujishiro, T., Hara, T. (2018). In Situ Observation of Hydrogen-Induced Cracking Propagation Behavior, Corros., 74, pp. 1054-1062. DOI: 10.5006/2757. 
[13] Terasaki, F., Ohiani, H., Ikeda, A., Nakanishi, M. (1986). Steel plates for pressure vessels in sour environment applications, Proc. Instn. Mech. Engrs., 200, pp. 141-158. DOI: 10.1243/PIME_PROC_1986_200_021_02.

[14]Zapffe, C., Sims, C. (1941). Hydrogen Embrittlement, Internal Stress and defects in steel, TMS-AIME, 145, pp. 225232.

[15] Tetelman, A.S., Robertson, W.D. (1963) Direct observation and analysis of crack propagation in iron-3\% silicon single crystals, Acta Metall., 11, pp. 415-426. DOI: 10.1016/0001-6160(63)90166-4.

[16] Winston, R. ed., (2011). Hydrogen-induced cracking and sulfide stress cracking, In: Uhlig's Corrosion Handbook, Hoboken, NJ, John Wiley \& Sons, Inc., pp. 183-194. DOI: 10.1002/9780470872864.ch15

[17] Feng, Y., Wang, H., Hou, F., Chen, H., Tan, P. (2015) Mechanism analysis of hydrogen blisters on the surface of a gas tank and research on its preventive measures. International Conference on Materials, Environmental and Biological Engineering (MEBE 2015), Guilin, China, 28-30 March. DOI: 10.2991/mebe-15.2015.133.

[18] Gibala, R. and Hehemann, R.F. eds., (1985). Hydrogen embrittlement and stress corrosion cracking, Metals Park, OH, ASM.

[19] Tanimura, M., Ishizawa, Y., Shimada, T. (1983). Nippon Kokan Tech. Rep., Overseas, 38, p. 42.

[20] Fan, J., Chen, H., Zhao, W., Yan, L. (2018). Study on flake formation behavior and its influence factors in Cr5 steel, Mater., 11, pp. 690-702. DOI: 10.3390/ma11050690.

[21] Oriani, R. (1972). A Mechanistic Theory of Hydrogen Embrittlement of Steels, Berichte der Bunsengesellschaft für physikalische Chemie, 76, pp. 848-857. DOI: 10.1002/bbpc.19720760864.

[22] Beachem, C. (1972). A new Model for Hydrogen-Assisted Cracking, Metall. Trans. A, 3, pp. 437-451.

[23] Nagumo, M. (2004). Hydrogen related failure of steels - a new aspect, Mater. Sci. Technol., 20, pp. $940-950$. DOI: $10.1179 / 026708304225019687$.

[24] Ren, X., Chu, W., Li, J., Su, Y., Qiao, L. (2008). The effects of inclusions and second phase particles on hydrogeninduced blistering in iron, Mater. Chem. Phys., 107, pp. 231-235. DOI: 10.1016/j.matchemphys.2007.07.004.

[25] Tiegel, M.C., Martin, M.L., Lehmberg, A.K., Deutges, M., Borchers, C., Kirchheim, R. (2016). Crack and blister initiation and growth in purified iron due to hydrogen loading, Acta Mater., 115, pp. 24-34. DOI: 10.1016/j.actamat.2016.05.034.

[26] Di Matteo, N.D. and Lampman, S.R. (1996). ASM Handbook, Volume 19: Fatigue and Fracture, Ohio, USA, ASM International.

[27] Iino, M. (1978). The extension of hydrogen blister-crack array in linepipe steels, Metall. Trans. A, 9, pp. 1581-1590. DOI: $10.1007 /$ BF02661940.

[28] Wilde, B.E., Kim, C.D., Phelps, E.H. (1980). Some observations on the role of inclusions in the hydrogen induced blister cracking of linepipe steels in sulfide environments, Corros., 36, pp. 625-632. DOI: 10.5006/0010-9312-36.11.625.

[29] Brown, A. and Jones, C. L. (1984). Hydrogen induced cracking in pipeline steels, Corros., 40, pp. 330-336. DOI: $10.5006 / 1.3593931$.

[30] Xue, H. B. and Cheng, Y. F. (2011). Characterization of inclusions of X80 pipeline steel and its correlation with hydrogen-induced cracking, Corros. Sci., 53, pp. 1201-1208. DOI: 10.1016/j.corsci.2010.12.011.

[31] Liou, H.Y., Wei, F.I., Wang, S.C., Shieh, R.I. (1993). Roles of Microalloying Elements in Hydrogen Induced Cracking Resistant Property of HSLA Steels, Corros., 49, pp. 389-398. DOI: 10.5006/1.3316066.

[32] Park, G.T., Koh, S.U., Jung, H.G., Kim, K.Y. (2008). Effect of Microstructure on the Hydrogen Rapping Efficiency and Hydrogen Induced Cracking of Pipeline Steel, Corros. Sci., 50, pp. 1865-1871. DOI: 10.1016/j.corsci.2008.03.007.

[33] Huang, F., Liu, J., Deng, Z.J., Cheng, J.H., Lu, Z.H., Li, X.G. (2010). Effect of microstructure and inclusions on hydrogen induced cracking susceptibility and hydrogen trapping efficiency of X120 pipeline steel, Mater. Sci. Eng. A, 527, pp. 6997-7001. DOI: 10.1016/j.msea.2010.07.022.

[34] Domizzi, G., Anteri, G., Ovejero-Garcia, J. (2001). Influence of sulphur content and inclusion distribution on the hydrogen induced blister cracking in pressure vessel and pipeline steels, Corros. Sci., 43, pp. 325-339. DOI: 10.1016/S0010-938X(00)00084-6.

[35] Condon, J.B., Schober, T. (1993). Hydrogen bubbles in metals, J. of Nucl. Mater., 207, pp. 1-24. DOI: 10.1016/0022-3115(93)90244-S.

[36] Ren, X.C., Zhou, Q.J., Shan, G.B., Chu, W.Y., Li, J.X., Su, Y.J., Qiao, L.J. (2008). A nucleation mechanism of hydrogen blister in metals, Metall. Mater. Trans., 39A, pp. 87-97. DOI: 10.1007/s11661-007-9391-3.

[37] Garofalo, F., Chou, Y.T., Ambegaokar, V. (1960). Effect of hydrogen on stability of micro cracks in iron and steel, Acta Metall., 8, pp. 504-512. DOI: 10.1016/0001-6160(60)90103-6.

[38] Lee, J.-L., Lee, J.-Y. (1987). The effect of lattice defects induced by cathodic hydrogen charging on the apparent diffusivity of hydrogen in pure iron, J. Mater. Sci., 22, pp. 3939-3948. DOI: 10.1007/BF01133343. 
[39] Laureys, A., Claeys, L., De Seranno, T., Depover, T., Van den Eeckhout, E., Petrov, R., Verbeken, K. (2018). The role of titanium and vanadium based precipitates on hydrogen induced degradation of ferritic materials, Mater. Charact., 144, pp. 22-34. DOI: 10.1016/j.matchar.2018.06.030.

[40] Laureys, A., Pinson, M., Depover, T., Petrov, R., Verbeken, K. (2019). EBSD characterization of hydrogen induced blisters and internal cracks in TRIP-assisted steel, Mater. Charact., In press, corrected proof. DOI: $10.1016 /$ j.matchar.2019.110029.

[41] Pérez Escobar, D., Depover, T., Duprez, L., Verbeken, K., Verhaege, M. (2012). Combined thermal desorption spectroscopy, differential scanning calorimetry, scanning electron microscopy and X-ray diffraction study of hydrogen trapping in cold deformed TRIP steel, Acta Mater., 60, pp. 2593-2605. DOI: 10.1016/j.actamat.2012.01.026.

[42] Mostafapour, A., Ebrahimpour, A., Saied, T. (2016). Identification of retained austenite, ferrite, bainite and martensite in the microstructure of TRIP steel, Int. J. Iron Steel Soc. Iran, 13, pp. 1-6.

[43] Balachandran, G. (2018). Challenges in special steel making, IOP Conf. Series: Materials Science and Engineering, 314, pp. 012016. DOI: 10.1088/1757-899X/314/1/012016.

[44] Vorob’ev, N. I., Mirzaev, D. A., Tokovoi, O. K., Yakovleva, I. L., Fominykh, E. A. (2006). Sulfides in Forgings of 40KhGM Structural Steel, Russian Metallurgy (Metally), 2006, pp. 119-125. DOI: 10.1134/S0036029506020030.

[45] Doig, P. and Jones, G.T. (1977). A Model for the Initiation of Hydrogen Embrittlement Cracking at Notches in Gaseous Hydrogen Environments, Met. Trans. A, 8, pp. 1993-1998. DOI: https://doi.org/10.1007/BF02646573.

[46] Huang, F., Li, X.G., Liu, J., Qu, Y.M., Ji, J., Du, C.W. (2011). Hydrogen-induced cracking susceptibility and hydrogen trapping efficiency of different microstructure X80 pipeline steels, J. Mater. Sci., 46, pp. 715-722.

DOI: https://doi.org/10.1007/s10853-010-4799-3.

[47] Dong, C.F., Xiao, K., Liu, Z.Y., Yang, W.J., Li, X.G. (2010). Hydrogen induced cracking of X80 pipeline steels, Int. J. Min. Mater. Sci., 17, pp. 579-586. DOI: 10.1007/s12613-010-0360-2.

[48] Kim, W.K., Koh, S.U., Yang, B.Y., Kim, K. Y. (2008). Effect of environmental and metallurgical factors on hydrogen induced cracking of HSLA steels, Coros. Sci., 50, pp. 3336-3342. DOI: 10.1016/j.corsci.2008.09.030.

[49] Koyama, M., Tasan, C.C., Akiyama, E., Tsuzaki, K., Raabe, D. (2014). Hydrogen-assisted decohesion and localized plasticity in dual-phase steel, Acta Mater., 70, pp. 174-187. DOI: 10.1016/j.actamat.2014.01.048.

[50] Chan, S. (1999). Hydrogen trapping ability of steels with different microstructures, J. Chin. Inst. Eng., 22, pp. 43-53. DOI: $10.1080 / 02533839.1999 .9670440$.

[51] Novak, P., Yuan, R., Somerday, B., Sofronis, P., Ritchie, R. (2010). A statistical, physical-based, micro-mechanical model of hydrogen-induced intergranular fracture in steel, J. Mech. Phys. Solids, 58, pp. 206-226. DOI: $10.1016 /$ j.jmps.2009.10.005.

[52] Mirzayev, D. A., Fominykh, E. A., Tokovoi, O. K., Vorob’ev, N. I., Shaburov, D. V., Yakovleva, I. L. (2007). Scanning electron microscopy of the flake structure in the forgings of structural alloy steel containing $0.4 \%$ carbon, Phys. Met. Metall., 103, pp. 292-298. DOI: 10.1134/S0031918X07030106.

[53] Pérez Escobar, D., Depover, T., Wallaert, E., Duprez, L., Verhaege, M., Verbeken, K. (2012). Thermal desorption spectroscopy study of the interaction between hydrogen and different microstructural constituents in lab cast Fe-C alloys, Corros. Sci., 65, pp. 199-208. DOI: 10.1016/j.corsci.2012.08.017. 